\title{
Emerging Risks: Methodology, Classification and Policy Implications
}

\author{
Ortwin Renn \\ Stuttgart Research Center for Interdisciplinary Risk and Innovation Studies, Stuttgart University \\ Seidenstr. 36, D-70174 Stuttgart, Germany \\ E-mail: ortwin.renn@sowi.uni-stuttgart.de \\ Received 10 August 2014 \\ Accepted 15 August 2014
}

\begin{abstract}
Good risk governance seems to rest on the three components: knowledge, legally prescribed procedures and social values. All three components are of particular importance for assessing and managing emerging risks, which are characterized by a lack of knowledge about the likelihood and magnitude of potential positive and negative consequences. This paper reports first about a protocol of how to govern emerging risks and then analyses the patterns of risks that would fall under the emerging risk category. Six patterns were identified: system breakdown risks, amplifier risks, highly volatile and pervasive risks, psychosomatic risks, social risks, and knowledge management risks. For each of these risk patterns, the main characteristics and the policy implications are described and analyzed.
\end{abstract}

Keywords: Emerging risk, risk governance, International Risk Governance Council (IRGC), risk management protocol, risk patterns, risk-policies

\section{Introduction}

Emerging risks are the result of new or future threats, where there is low level of knowledge (or no knowledge at all) about the potential losses as well as the probability distribution of their occurrence (OECD, 2003). In some cases, this knowledge may be contested among actors with different interests or viewpoints. Conventional approaches to projecting loss size, relative frequencies or probability distributions over time or severity of consequences are consequently most often ineffective if applied to emerging risks. Attempts to assess emerging risks with technical or scientific instruments may prove inadequate as scientific understanding of emerging risks can change rapidly. Therefore, adaptability and flexibility are vital to manage emerging risks in terms of individual, social, and economic impacts (Kocharov, 2010).

The International Risk Governance Council (IRGC) defines emerging risks as those types of risks, which are new, or familiar risks in new or unfamiliar conditions
(IRGC, 2009). Emerging risks refer to threats that are perceived to be potentially significant but which may not be fully understood or assessed, thus not allowing risk management options to be developed with confidence. Some emerging risks do not prove to be as significant as originally feared but others might prove to be worse than expected, with a high potential for loss of safety margins.

Emerging risks can be further broken down into three distinct, but overlapping categories, based on their main characteristic at a certain stage. These categories are described as follows (Mazri and Florin, 2014):

- Emerging technologies with emerging risk profile based on high uncertainty and lack of knowledge about potential impacts and interactions with the affected risk absorbing systems. Nanotechnology and many other new technological developments would fit that description.

- Emerging technological systems with emerging interactions and systemic dependencies. The main issue here is the not the risk of the technologies 
(that may be known or well estimated) but the interactions of these risk (and also benefits) with other types of risks or activities that could lead to non-linear impacts and surprises. Examples here are biofuels, climate change issues, all kind of IT related risks, and critical infrastructure issues.

- Established technologies in a new emerging context or environment: The main problem here is that familiar technologies are operated in a new context or in different organizational settings that may change both the probability as well as the magnitude of potential impacts. One could also include here risks driven by complacency and overconfidence on one's own ability to cope with sudden crisis. Examples here are established technologies as a target for terrorist attacks, technologies in context of social or societal crisis (like civil unrest); new stress situation due to organizational changes such as mergers or just-intime production or the shift from public to private services.

New assessment and management methods and procedures are particularly needed for emerging risks. They are at the crossroads between natural events (partially altered and amplified by human action such as the emission of greenhouse gases), economic, social and technological developments and policy driven actions, both at the domestic and the international level. Emerging risks also face specific problems with respect to public perception and risk governance structures. Risk management and governance processes dealing with emerging risks suffer from a loss of prior knowledge and frequently public plausibility.

This paper has made the attempt to identify and classify some of the most likely candidates for emerging risk on all three levels described above. Section 2 will describe the environmental and social context in which new emerging threats may arise. Section 3 will introduce a protocol that the IRGC has developed for identifying and managing emerging risks. This protocol will be applied to a set of global risk scenarios developed by leading institutions such as the World Economic Forum. Six risk clusters emerged from this analysis as likely candidates for new emerging threats. Each of these clusters is briefly described in section 4 . The conclusions summarize the results and provide an outlook for future challenges.

\section{The Context for Emerging Risks}

The context for emerging developments and threats is characterized by increased vulnerabilities and interconnections between geographic areas as well as functional dependencies between the various sectors of society such as the physical world, the economy, the social relationships and the political cultures (Stern, 2013). The potential for new risks to involve is likely to become augmented because of:

- increase of population and population density ${ }^{1}$;

- increase of population exposed to natural hazards and technological risks (dramatic increase in losses due to natural disasters over the last four decades, during the last decade natural hazard disasters have resulted annually in some 79,000 fatalities, with 200 million people affected $)^{2}$;

- increased use of hazard-prone land for productive purposes (for example 40 of the 50 fastest growing urban centres in the world are located in earthquake-endangered areas) (Randall et al. 1996);

- increased interdependencies between natural, technical, social, and cultural hazards (FischerKowalski and Amann, 2001);

- expected increase of hazard intensity due to climate change and other human interventions into geochemical cycles (Rosa and Dietz, 2010);

- growing diversity with respect to lifestyles and subcultures within societies (Beck, 1992; Beck, 2000).

At a time, when the disaster potential increases, the coping mechanisms of many societies appear to become less effective. Vulnerability is likely to increase due to (Rosa et al. 2004):

- speed of urbanization (probably two thirds of the world population will live in cities after 2020) (Jones and W.A. Kandel, 1992);

- insufficient speed in building infrastructure to cope with it $^{3}$;

- coupling of independent risk sources (Perrow, 1984)

1 According to the medium variant of the 2010 Revision of World Population Prospects, the world population is expected to increase from 6.9 billion in mid-2011 to 9.3 billion in 2050 and to reach 10.1 billion by 2100 . http://esa.un.org/wpp/Analytical-Figures/htm/fig 1.htm (accessed: July 10, 2014)

2 Munich Reinsurance (2013): NatCatService, Munich-Re: Munich. See also: OECD (2003), p. 14.

3 OECD (2003), 44ff 
- interaction of natural disasters with chemical, technological, lifestyle, and social risks ${ }^{4}$;

- increase of mobility, migration and cultural derooting (Black et al. 2013)

- loss of traditional management capabilities ${ }^{5}$;

- increase of social pressure and conflicts (Iadociola and Shupe, 2013);

- lack of capacity for mitigation and contingency management, etc ${ }^{6}$.

Given these new challenges the world needs a concerted effort to deal with emerging risks. In particular new methodological as well as institutional solutions involving the different levels of risk governance at the local, national, international and global level are required as a means to provide adequate tools for limiting and managing the new emerging threats that will be embedded in the context of the global changes and challenges listed above (Renn, 2008).

\section{The IRGC Protocol for Classifying Emerging Risk Clusters}

What are eligible criteria to characterize risks that are not yet visible on the monitoring screen of risk management institutions? Many risk management and governance institutions have been working on a methodology or a protocol to identify emerging risk or to propose a methodology of how to identify these risks. For our analysis I will use an approach that has been recently advocated by the International Risk Governance Council (IRGC) ${ }^{7}$. The protocol for identifying emerging risks is based on five steps, shown in Fig. 1.

$4 \quad$ World Economic Forum (2013): Global Risks 2013. 8. Edition. WEC: Geneva, pp. 63f. http://www3.weforum. org/docs/WEF_GlobalRisks_Report_2013.pdf (access: August 10)

5 Wissenschaftlicher Beirat der Bundesregierung Globale Umweltveränderungen (WBGU) (2000): World in Transition: Strategies for Managing Global Environmental Risks. Springer: Berlin.

6 International Federation of the Red Cross and Red Crescent Societies (2013): World Disasters Report 2013. International Federation: Geneva.

7 The following paragraphs are partially taken from: IRGC (2010): The Emergence of Risk. Contributing Factors. IRGC: Geneva and IRGC (2014): Emerging Risk Governance Protocol. Extended Version. Written by C. Mazri and M.-V. Florin. IRGC: Lausanne

\section{STEP 1: Make sense of the presence and explore the future}

This first step of the IRGC protocol aims to describe the current and possible future contexts, in which risks and opportunities may develop. It provides an understanding of the whole process with the required inputs from the environment regarding potential existing or emerging threats and opportunities. This step aims to continuously screen and make sense of the context, in which risk management takes place, and to feed the whole emerging risk governance process with reliable and updated inputs. The main goal is early warning or identification of potential threats to the organization.

\section{STEP 2: Developing scenarios based on models AND narratives}

At this stage, risk management agencies or organizations have identified threats and opportunities that deserve further analysis for exploring their impacts on risk governance in the future. By adopting a forwardlooking approach, this second step will rely on scenarios and narratives to describe how these threats and opportunities may become risks that require management or competitive advantages that can be seized. Developing scenarios implies a p rocess of looking to the future and developing possible stories about how the future may unfold. Scenarios represent combinations of formal models and plausible narratives (Helgeson et al. 2013). Depending on the topic and the state-of-the-art of available knowledge, scenarios differ in the composition of formal modeling and storytelling. Some scenarios pursue well-known causal or functional relationships and vary only in their assumptions. In contrast, others come close to science fiction stories developing imaginative futures based on basic knowledge, formal logic and plausibility. Almost all scenarios include methods for involving multiple actors and perspectives in describing what the future could look like. This is an open process and the resulting output represents the views of the participants.

Scenarios are not predicting the future. In the specific context of emerging risk governance, scenarios are rather meant for structuring and organizing the deep uncertainties decision makers are confronted with when anticipating the possible future threats and opportunities. They are constructed with the goal to enhance the ability to deal with the inherently uncertain and complex character of different and heterogeneous 


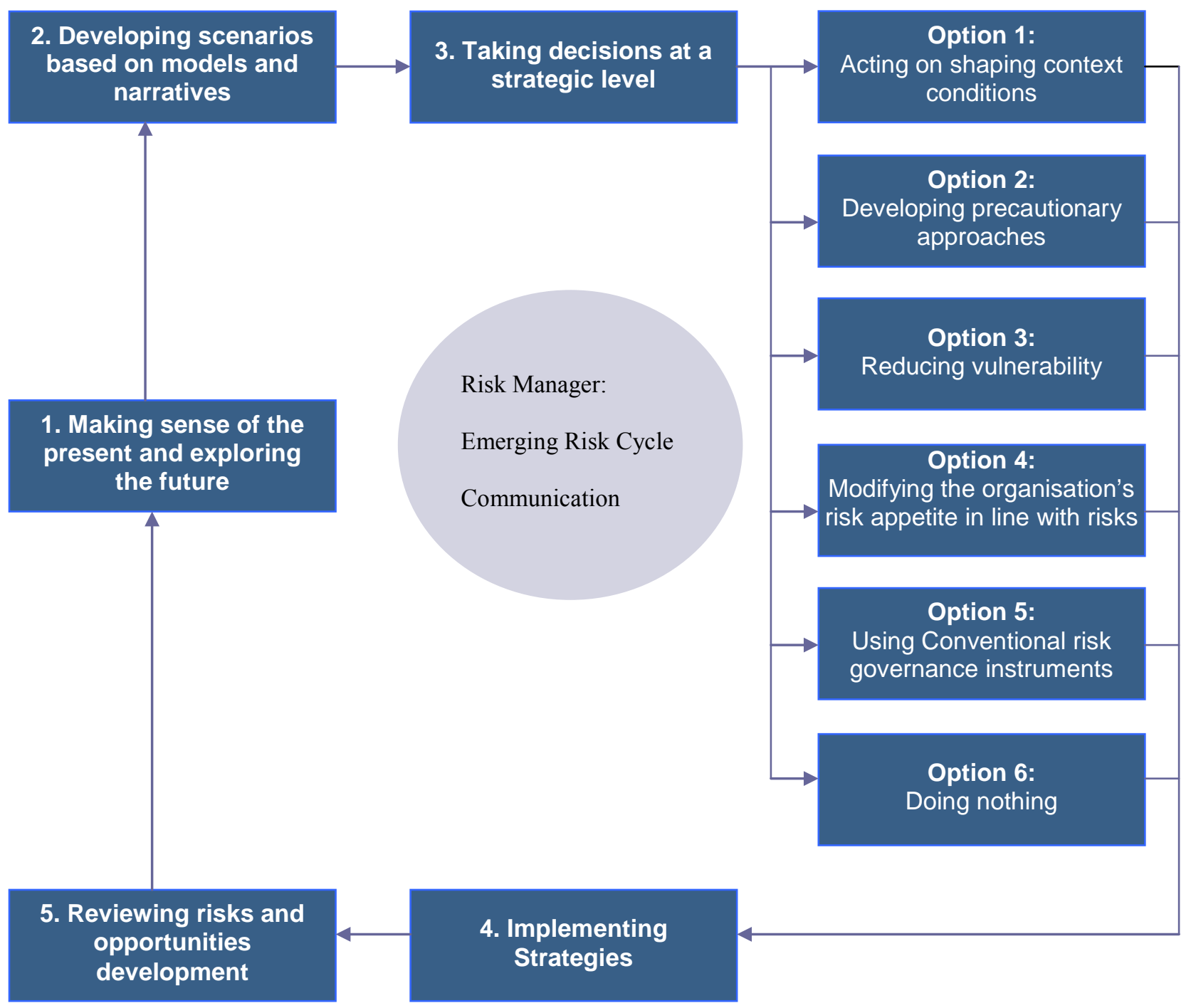

Fig. 1. IRGC Emerging Risk Governance Protocol.

social and cultural environments (Healey and Hodgkinson, 2012). The benefits of these approaches range from considering uncertainty in strategic decision making to organizational learning and the construction of common understanding among participants.

The objectives of this second step are therefore to:

- Develop as detailed as possible scenarios exploring the possibility that threats and opportunities will affect risk management in the future.

- Provide evidence and support for future decisions about the threats and opportunities identified in the first step.
- Continuously update these scenarios according to changes observed in the environment and knowledge evolution.

\section{STEP 3: Strategic decision making}

An important component of effective emerging risk governance is making the right decision at the right time. This exercise implies linking decision science with traditional risk governance, especially in the face of situations that are new, complex, uncertain or ambiguous. The purpose of the third phase of the protocol is to exploit all the scanning, sense-making and foresight capabilities deployed in the previous phases to 
generate and select proactive strategies in dealing with emerging risks.

Practically, this implies to:

- Explore and identify opportunities for decisions, according to scenarios developed at step 2 .

- Explore and describe the set of possible decision options. A t this stage, no option should be excluded.

- Identify windows of opportunity within each scenario that provide the most adequate conditions for initiating effective interventions.

- Identify thresholds of irreversibility after which interventions would no longer be effective.

- Define criteria for each intervention point for selecting, among the various options identified, those that align with the decision maker's strategy for dealing with emerging risks. This is done according to the selected decision-making style and appetite for risk.

- Decide which emerging risk management option(s) will be implemented.

- Communicate about this process in a transparent manner.

\section{STEP 4: Strategic option selection}

The IRGC protocol discusses six different strategic options that may result from a thorough analysis in the third step:

a) Acting on context-shaping conditions: The first strategy is to change, modify or manipulate the context conditions that could lead to an emerging threat. One could for example decouple mutually dependent risk sources, remove risk amplifiers from the local risk source or train people to avoid specific situations that could lead to emerging risks. If context variables that matter are known and also changeable by the risk decision maker, this is the preferred option for risk management as it keeps the opportunities alive and prevents the risk to emerge. Such ideal situations are rarely given but one can at least search for strategies to make context conditions more risk averse.

b) Developing precautionary approaches: Aiming to avoiding the risk -or at least avoiding the occurrence of any irreversible consequence of the risk- could represent a valuable decision option in cases where a risk evaluation leads to high fears of unacceptable consequences. Within this category of options, consideration and work should accordingly be dedicated to identify possibilities of actions where opportunities are maintained but the likely consequences of risk exposure are limited and at least partially reversible. Of course, this subtle balance cannot be maintained forever and it is important to identify the point where actions that are more decisive may need to be taken.

c) Reducing vulnerability: If the decision making body cannot identify any opportunity for action on the sequence of events described in the scenario or if this intervention is considered inappropriately or too costly, reduction of exposure or vulnerability to the risk agent can be a strategic option. To do so, several possibilities can be considered:

- Reducing sensitivity to the risk by developing redundancies, improve personnel training or readjust protection capabilities. For instance, in the case of extreme events from natural hazards such as hurricanes, flooding, heat waves, or pandemics, one can base the protection strategy on the worst-case scenario in order to reduce the vulnerability to the potentially affected population. However, this comes at a cost which may not be affordable.

- Building resilience and adaptation abilities to prepare for unexpected events. This strategy implies going beyond the anticipated worstcase scenarios to ensure that organisations will be able to rebound after any shock, adapt to any new circumstances and recover from unknown types or levels of stress. Decentralizing decisions, enabling self organisation and social networking, and promoting diversity are examples of approaches allowing for resilience development.

d) Modifying the decision maker's risk appetite in line with a new risk: The 2008 financial crisis revealed a significant imbalance between the risks some financial institutions were willing to take (risk appetite) and their risk taking capacities (the maximum amount of risk they can sustain, or their tolerance to risk) (Barfield, 2007). Among other consequences, this has demonstrated the need for increased transparency in financial governance and 
for better consideration of risk appetite and risk taking capacity.

e) Resort to conventional risk management: This type of option for emerging risk management is partcularely relevant in cases where known risks develop in new or changing context conditions. It this case, it is reasonable to consider risk management options for familiar (as opposed to emerging) risks. T he risk mechanisms are well known but the governance would need to be revised in $t$ he light of the new contextual developments. The most challenging part when dealing with these risks is therefore the awareness of the contextual evolution.This option would apply, for example, if malaria would develop in Europe (or in general to higher latitudes), as a consequence of climate change.

f) Doing nothing: If, at the end of step 3, the decision makers conclude that the scenario/ narrative of a certain potential threat (identified at step 1) does not lead to anticipation that the threat will develop as a risk to the potentially affected popukation, then they can propose to "do nothing". This means that the threat is not considered by the decision makers as plausible enough, or its impact is considered as negligible, to trigger any action at the present time. This does not prevent risk managers from doing more monitoring, as things may change over time.

The six types of options described above are suggestions and starting points to trigger reflection and creativity in generating strategies. Enhanced creativity and imagination in this exercise is likely to provide decision makers with more satisfactory strategies in the third and fourth step.

\section{STEP 5: Reviewing risk development and decision}

After the decisions have been taken (step 3) and implemented (step 4), it is necessary to monitor how threats and opportunities unfold and review the relevance of decisions made. The monitoring of consequences of decisions taken and their systematic review is a k ey step in each governance process. It provides decision makers with the ability to revise their decisions if necessary and to adapt them as knowledge becomes available and as the context changes. In the context of emerging risk governance, both monitoring and reviewing become even more crucial as the whole protocol is expected to provide the decision making body with proactive capabilities. The final objectives of step 5 are therefore to:

- Demonstrate that the decision-making body is performing effectively in dealing with opportunities and risks that emerge from changing and evolving contexts. By pursuing a pathway of adaptive mangement, the decision makers learn step by step how to implement the decision and to monitor its intended and unintended consequences

- Provide valuable feedback loops to reiterate steps 1 and 2 of the process.

- Provide insights on the protocol's strengths and weaknesses (engaging in a reflexive process).

The protocol is a systematic and replicable framework with the aim to support decision makers in defining and revising strategies for emerging risk governance. It aims to cover all stages of risk emergence, from early signals of emergence of a risk until the risk materializes or disappears. It promotes and organizes the development of a s et of capabilities required to deal with complex, evolving and uncertain environments:

- Detect and interpret early the seeds of change that may create risks and/or opportunities in the present or future.

- Help decision makers imagine the future contexts with which they may be confronted if no actions are taken.

- Through communication, foster creativity and transparency when investigating possible decision options and identifying appropriate timing of intervention.

- Constantly monitor contextual changes and adapt the organization's pathway accordingly.

There are challenges associated with these tasks. Overcoming them is not only a matter of models and tools. It is also about creating organizational dynamics, building leadership at the senior level and overcoming cognitive limitations when confronted with deep uncertainties. Accordingly, a cr oss-functional coordination is crucial for steering the required resources and expertise towards the same direction, triggering and facilitating interactions and finally ensuring scientific soundness of the process. 


\section{A Systematic Review of Emerging Risk Clusters}

On the basis of the IRGC emerging risk protocol the author initiated a systematic inquiry into a set of potential candidates for emerging threats that matched one of the three emerging risk categories and that had been identified and explored by various teams of experts and practioners. The scenarios selected and analyzed for this exercise were taken from the OECD, the World Economic Forum, Swiss Re, the Bertelsmann Foundation and Risk Worlds ${ }^{8}$. These scenarios match the criteria developed for the first two steps of the IRGC protocol, i.e. context analysis (step 1) and narrative scenario writing (step 2). The author added some policy implications (step 3-5) at the end of each subsection. The summary categories used in this article to pool risks into clusters are created by the author and are meant to reflect and summarize the outcomes of the different scenario exercises. Methodologically, this could be classified as a narrative meta-analysis (Koricheva et al. 2013).

\subsection{Type 1: System breakdown risks (Including cyber-risks)}

System breakdown risks are characterized by a break in a causal hazard chain, and this can occur within financial systems as experienced in the 2008 crisis, communication network systems or natural hazard response or relief systems. The threat of system breakdown is a feature of an interconnected world and it exists at many levels, from local to global. The main cause for system breakdown is the lack of governance capability and coherence in the face of

8 How the emerging risk scenarios have been identified, analyzed and summarizes, has been described in detail in: Renn (2014). The sources for the scenarios are: OECD (2003): Emerging Risks in the 21st Century. An Agenda for Action. OECD: Paris; OECD (2012): Global Shocks: Improving Risk Governance. OECD: Paris; Löfstedt, R. (ed.) (2003): Riskworld. Risk Research, 6 (1-4), 289-619; World Economic Forum (2013): Global Risks 2013. WEC: Geneva; Swiss Re (2012): Identifying Emerging Risk Zuerich http://www.swissre.com/rethinking/emerging_risks/ emerging_riskhtml (access: July, 19, 2014);

Arpe, J.; Glockner, H.; Hauschild, H.; Petersen, T.; Schaich, A. und Volkmann, T. (2012): Die ökonomischen Risiken der Globalisierung. Ergebnisse einer Experten- und einer Bürgerbefragung. Global Choices, 1. Bertelsmann Stiftung: Osnabrück, Germany. interconnectedness of localities and functional systems ${ }^{9}$. The coping mechanisms in place to manage these risks vary across countries and at global level. System breakdown risks are not severely affected by societal risk perception or cultural views - it is the "visible" breakdown risks that have to be addressed and managed.

System Breakdown risks are promoted by:

- interconnectivity of hazardous systems such as natural and technological (water dam built in an earthquake prone zone);

- increase of vulnerabilities by constructing a multitude of low-probability, high-consequence technological devices (such as a liquid gas terminal next to a chemical factory);

- transfer of hazardous technologies in politically unstable or potentially violent societies;

- increased mobility of humans through migration and tourism (The world tourism organization counts on 1602 million tourist arrivals in 2020) ${ }^{10}$; and

- move into impact dimensions that show non-linear patterns.

The last point deserves some more explanation. All cause-effect functions are linear if the Delta increase is purely incremental and if the present location of the system on the cause-effect function is distant from possible non-linear thresholds (Ulanowicz, 2013). Both conditions may be jeopardized in the face of more recent developments. First, many technological, economic and social changes occur more rapidly than in the past making larger than incremental steps more probable. Second, human activities have the potential to affect the ecological, economic and social fabric of human existence more profoundly than in the past. Many analysts have called this the "intensity factor"(Gheorghe and Vamanu, 2004). The intensity of impacts has grown and, along with the increased influence on the existing systems, the likelihood that we are approaching non-linear thresholds increases as well.

There are three prominent examples in this field: the first one is infectious disease, the second one nutrition, and the third infrastructure failure. The first two threats

9 Governance deficits were mentioned as the main cause of emerging risks in all of the analyzed documents. An early version of this problem has been described in Castells, M. (1996): The Rise of the Network Society. Blackwell: Oxford.

10 OECD (2003), p. 24 
are related to a basic evolutionary characteristic: The more "food" is offered on nature's market the more incentives are mobilized to use it as a new supply for other "hungry" organisms. This characteristic holds true in terms of volume of mutations as well as speed of evolution. As the number of humans approach 6.7 billion, the opportunity to serve as a food supply invites feeding organisms to utilize this cornucopian reservoir. In terms of evolutionary flexibility and mutational speed, this threat may be confined to microbes, in particular bacteria and viruses (Gaze et al. 2013; Håberg, 2013). They have extreme adaptations capabilities and their mutation rate is fast and effective. Major sources for new infections may be the transfer of animal viruses onto humans as well as specialised bacteria that develop resistance against antibiotics. The spread of these newly developed microbes is facilitated and promoted through mobility (Garrett, 1995). The Centre of Disease Control in Atlanta discovers a new virus or strain of bacteria almost every month (CDC, 2000). So far, modern pharmaceutical technology has been able to combat most of the newly evolved infections. Yet the example of Aids, and more recently Ebola, exemplifies that a single failure in this attempt can cost millions of lives. Furthermore, global environmental change can transport infectious diseases in areas that have not been accustomed to this new threat before (Lipp et al. 2002).

The second example is food supply for human consumption. The number of people is, of course, related to the volume of food produced to feed these people. Such a r eservoir of nutrients attracts other organisms that would like to feed on them (Mahul and Gohin, 1999) ${ }^{11}$. Again microbes are here of most eminent importance, but fungi and insects may also play a role. This threat is amplified by the continuous trend towards less and less plant species used for human consumption $^{12}$. At this point in time, almost $80 \%$ of all serial food is confined to seven different plants. Wheat and rice alone account for almost half of the world's serial production. If anyone of these central serial species became infected by a new type of disease for which human ingenuity had no immediate cure

11 See also: Wissenschaftlicher Beirat der Bundesregierung Globale Umweltveränderungen (WBGU) (2000): World in Transition: Strategies for Managing Global Environmental Risks. Springer : Berlin, pp. $81 \mathrm{ff}$.

12 Wissenschaftlicher Beirat der Bundesregierung Globale Umweltveränderungen (WBGU) (2000), pp. $93 \mathrm{ff}$ available the world would face a s erious famine with catastrophic results.

The third example relates to technical infrastructure (Kröger, 2008; Llanso, 2013) $^{13}$. Human activities have become more and more interconnected and mutually dependent. Such networks are based on critical infrastructures such as transportation means, communication routes, energy supply and, most importantly, information and communication services. Many economic, political and social transactions rely on the availability and functionability of the existing infrastructure. As soon as infrastructural services are disturbed or malfunctioning, the original activity is likely to collapse and may infect other systems that rely on the well-functioning of the affected system. The most prominent example here is the emergence of more and more cyber-risks, including cyber-terrorism but also risks to privacy and civil liberties (Neitzke, 2008).

Modern societies are characterized by an increasing vulnerability that will make system breakouts more probable, and awareness of the counter-movements has increased since the $11^{\text {th }}$ September attack. There is now a competition race to improve resilience of all kinds of systems (Hémond and Robert, 2012; Gallopin, 2006) ${ }^{14}$. For example the US Defence Department has protected its system by creating isolated islands where sensitive information is physically disconnected from the system rather than using firewalls for protection. This lack of connectivity could create their own risks, as the new system will only work if the division line between systems is self-reliant, and where there is problem of vital information not being available on a bounded system.

What kind of policy options (Step 4 and 5) would be available and recommendable for this emerging risk? The ideal societal response to these types of risks would be a g lobal risk management board, at the OECD or global level. Due to the interconnected nature of the

13 See also: The White House (2013). Critical Infrastructure Security and Resilience. Presidential Policy Directive/PPD-21, February 12, 2013. Archived by WebCite ${ }^{\circledR}$ at: http://www.webcitation.org/6Q3iVRi UP. (access: August 4, 2014)

14 In particular to the threat of terrorism: Committee on Science and Technology for Countering Terrorism (2002): Making the Nation Safer: The Role of Science and Technology in Countering Terrorism. National Research Council: National Academies Press: Washington D.C. 
risk, a national or trans-national forum (such as the European Union) would be insufficient. There are a number of major constraints to achieving such a global risk management board. Every system invites freeriding, and a global system that managed and enforced standards would also threaten the advantages for freeriders (Dietz et al. 2003; Falk et al. 2010). Similarly, there are always winners when a s ystem collapses, so there would be countries or institutions that stood to gain by not participating or obstructing the creation of a comprehensive response to these system breakdown risks. Therefore, the creation of an International Risk Governance Council such as the IRGC has been particularly relevant for this new cluster of risks.

The implications for risk management are substantial. The potential costs of such disasters are beyond the scope of what even reinsures are able to pay. Around 13 million people die every year from infectious diseases, primarily measles, pneumonia, cholera, AIDS, tuberculosis and malaria ${ }^{15}$. Failures of infrastructure, in particularly dams and high-rises, cost thousands of lives each year. Some analysts estimated that a total collapse of the Three-Gorges-Dam presently built in China could kill as many as 1.3 mio people (WBGU, 1999). A series of risk assessments over the world demonstrates increasing rather than decreasing catastrophic potential over the last two decades (Barrett, 2014).

The probability for such damages to occur is difficult to calculate. This is particularly true for new health threats since mutations occur randomly and, in spite of an increased speed of mutations in the face of attractive food supplies, the most adaptive candidate may come up sooner or later (truly stochastic event). Even calculating failure probabilities for critical infrastructure has become increasingly difficult due to the dependencies of failures from operational error or even sabotage and terrorism (Aven and Renn, 2009). This makes it hard for risk management institutions such as insurers or regulatory agencies to deal with breakdown risk. In addition, such risks may percolate though almost all types of conventional risk governance policies, starting with individual health insurance to liability legislation and social security systems. The best what risk management agencies can do is to pursue the resilience-based strategy. i.e. to limit the catastrophic potential independent of the low probability of a

15

OECD (2003), p.15 catastrophic release and to strive for decoupling of interconnected risk-inducing activities.

\subsection{Type 2: Amplifier risks}

Amplifier risks originate as physical risks, which then extend into the financial, political and psychological worlds. The effects of these risks might not have as high a physical impact as other risks such as breakdown risks, but they share the attribute of having a highly symbolic value. These risks tend to become amplified in the form described by the theory of social amplification of risks (Kasperson et al. , 1998). The physical impact may be negligible but the quality or the circumstances of these impacts amplify these consequences in the perception of the observers and move them into behavioural activities that pose serious damage to society as a whole. Amplifier risks are usually characterized by high complexity, uncertainty and ambiguity (Renn, 2011).

Complexity refers to the difficulty of identifying and quantifying causal links between a multitude of potential candidates and specific adverse effects (Marshall, 2013). The nature of this difficulty may be traced back to interactive effects among these candidates (synergism and antagonisms), long delay periods between cause and effect, inter-individual variation, intervening variables, and others. It is precisely these complexities that make sophisticated scientific investigations necessary since the cause-effect relationship is neither obvious nor directly observable. Complexity requires systemic assessment procedures and the incorporation of new mathematical tools such as non-linear regression and fuzzy set theory.

Uncertainty is different from complexity. It comprises different and distinct components. They all have one feature in common: uncertainty reduces the strength of confidence in the estimated cause and effect chain. If complexity cannot be resolved by scientific methods, uncertainty increases. Even simple relationships, however, may be associated with high uncertainty if either the knowledge base is missing or the effect is stochastic by its own nature.

The last term in this context is ambiguity or ambivalence (Renn and Klinke, 2012). This term denotes the variability of (legitimate) interpretations based on identical observations or data assessments. Most of the scientific disputes in the fields of risk analysis and management do nor refer to differences in 
methodology, measurements or dose-response functions, but to the question of what all this means for human health and environmental protection. Emission data is hardly disputed. Most experts debate, however, whether an emission of $\mathrm{x}$ constitutes a serious threat to the environment or to human health. Another question in this context is: Should regulation be confined to avoid significant health effects or should it be expanded to any measurable effect that could cause some still unknown damage (cf. the discussion on electromagnetic fields, EMF)? Again high complexity and uncertainty favour the emergence of ambiguity, but there are also quite a few simple and almost certain risks that can cause controversy and thus ambiguity.

The main feature of amplifier risks is that high complexity, uncertainty and ambiguity are all associated with risks of this type. The causal chain is highly complex encompassing different types of consequences ranging from loss of human lives to financial losses. Second, the risks are linked to high uncertainty, even indeterminacy because they are based on non-linear relationships. Thirdly, the consequences are evaluated differently depending on social position, status and economic well-being. These damages include consumer boycotts, stock devaluation, removal of trust and confidence in risk management agencies and others.

Until now, risk management agencies have not adequately addressed these new amplifier risks. What is clearly needed, is a holistic and systemic concept of how to characterize, assess, and evaluate these risks. In addition, risk managers need to clarify what type of procedure is demanded for obtaining effective, efficient and politically feasible risk reduction results for coping with this risk cluster.

'Mad Cow Disease' or BSE appears to be the perfect example of an amplifier risk (Dressel, 2000). The BSE crisis occurred on the time between 1985 and 1996, the year when BSE was discovered and the year when the transmission to humans became the most likely explanation for the occurrence of a $n$ ew variant Creutzfeldt-Jakob disease. Although the physical risk to human health turned out to be relatively small (in all of Europe less than 150 cases of CJD), the repercussions on financial, economic, political and social affairs was tremendous. The cumulative expenditure by UK agricultural departments in response to the BSE crisis, from 1996 to 2001, was estimated to have reached GBP 4.2 billion. The bulk of the expenditure has been given for compensation of commercial enterprises, especially compensation to farmers for the removal of cattle over 30 months of age from the human food chain and support to the slaughtering and rendering industries. Other costs since 1996 that have been borne by public expenditure include the public inquiry into BSE, at an estimated GBP 25 million (BSE Inquiry, 2001). The costs to the private sector of BSE have also been considerable. The ban on British beef exports in March 1996 led to the complete loss of a trade worth GBP 700 million per year. In the first 12 months since March 1996, the total value of the market for UK produced beef fell by an estimated $36 \%$ in real terms (a combination of loss of exports and the drop in domestic demand), amounting to an estimated loss of value added to the UK economy of GBP 1.15 billion. In addition to these economic problems, consumers lost faith in the regulatory system, political officials were forced out of office and all over Europe new food agencies were founded or old ones restructured.

One of the initiating events for the disaster to happen was the decision to lower combustion temperature for animal feed. This decision was based on a cost-benefit analysis, which demonstrated a gain of max. GBP 30 million for doing so. At the time several scientists warned the British Agricultural Ministry to use more caution in this field as cows may be more sensitive to pathogens in animal feed since being vegetarians they have not developed any resilience against animal-borne diseases. It is certainly not proven that lowering the temperature has been the main reason for the spread of BSE, yet the case demonstrates the narrow focus under which such a decision was made. The consequences that followed have changed the regulatory landscape in Europe and cost taxpayers multi-million losses. Retroactively, everyone knows better, but if a Council of interdisciplinary scientists had been given the opportunity to review the situation, one could at least be more confident that the risks would have been appraised in a more competent manner.

How can one deal with these amplifier risks? An idealized societal response to these risks would be the formation of cross-disciplinary risk management agencies, perhaps situated within existing institutions. In the terminology of the IRGC strategies this would be equivalent to reducing vulnerabilities. Such agencies would be required to link the physical, financial and political (governance) links between the risks. The 
symbolic aspects cannot be addressed in isolation from the links, but without the symbolic assessment the links would pass unnoticed. Institutional fragmentation and disciplinary thinking pose constraints to this type of societal risk management structure. In addition, the rationality of decision-makers and risk managers tends to underestimate the symbolic value of certain risks.

\subsection{Type 3: Highly volatile and pervasive risks}

These risks cover those human activities that promote rapid environmental or cultural changes without proper knowledge of the consequences. Trial and error, the usual method of testing innovations, may be unacceptable because the error is so costly in terms of human lives or money that nobody is prepared to pay for them. In addition, because of the complex nature of these risks, outcomes can often not be associated with direct causes. Therefore, impacts are simulated with computer models as a means to avoid the real trial and error experience. The validity of such modeling efforts, however, remains contested (Wildavsky, 1979). Such risks are inherently both uncertain and unpredictable. All systems can cope with change if it is gradual enough to allow for adaptability, but the issue with these types of risks is the speed of change. There are many cases where a pervasive risk has been introduced, which has created profound changes that have not been good for humans.

The best example is global change (National Research Council, 2010). This problem is normally framed as an environmental threat. Rarely have risk assessment methods been used for dealing with this issue. Yet there is an increasing amount of evidence that many natural disasters are being caused or promoted by global change. Although it is too early to attribute the increasing losses of natural disasters to global climate change, it is an experiment with uncertain but potential catastrophic outcomes for human civilization (Helmer and Hillhorst, 2006). Climate change is only the spearhead of a class of risk that can be characterized as global interventions of humans in natural cycles. The problem here is that the resulting effects are still widely uncertain but there is also hardly any escape for any society to avoid being affected when the worst case is going to happen. ${ }^{16}$

Renn (2014), pp.367ff.
A second example is related to basic innovations such as nano-technology (Shatkin, 2013). It is a truism that the risks and benefits of new technologies are uncertain as long as the scope of impacts is still unclear. Problems occur, however, if, as stated above, the usual path of trial and error cannot be followed because the error is beyond what societies are willing to pay in terms of a risk premium. This price is determined by two components:

- the preferences of (affluent) societies to tolerate new unknown risks (aversion factor) and

- the potential intensity of impacts that might be expected from these new technologies.

With respect to Nano-technologies analysts such as Bill Joy have warned the public that the impact of these new technologies in terms of social costs will outweigh the potential benefits by far (Joy, 2000). Innovation may become impeded from two sides: the high risk aversion factor of most people in industrial societies and the high impact factor for risks across the board of dimensions (health, environment, political, psychological) associated with new technologies.

In response to this type of emerging risk the IRGC protocol would probably recommend to pursue the precautionary concept. An ideal institutional management mechanism would be based understanding on the precautionary approach as part of the regulatory regime, not only with regard to the effects, i.e. the known impacts, but also focusing on the process, i.e. the speed of change (Klinke and Renn, 2001). It is not always possible to have control over this speed, and it would take a very courageous effort to pay special attention to the speeding up processes, even where the negative impacts are not noticeable.

The precautionary principle, if well understood, provides an institutional means for increasing reversibility, if the processes are found to be more negative than initially perceived (Bennet, 2000). Such an approach is the more necessary the more ubiquitous, persistent and accumulative a $r$ isk appears to be. Ubiquity, persistence and accumulations are indicators for irreversibility, and should the alarm be sounded, society has to ensure controllability and reversibility in the face of risk. For example, the European regime for nanoparticles in food and cosmetics has not banned their use, but has tried to ensure that a gradual application in the market will allow the possibility of retreat should the risks turn out to be damaging (Grobe et al. 2008). 
Simultaneously, they have introduced financial subsidies to develop new detection and risk assessment methods.

A major constraint with the adoption of the precautionary principle is the potential for arbitrary judgments (Charnley and Elliott, 2000). There is a dilemma between the conflicting requirements for solutions fast enough to be innovative and slow enough to be reversible, in the face of scientific uncertainty. There are no simple negative/affirmative decisions, but a need to develop a set of good criteria for judging the right balance and speed of change. At global level, there is a growing scientific movement pressing for precaution. There is now a strong interest to find better regulatory regimes to balance speed of change with the necessity of innovation.

High uncertainty risks demand management efforts based on market incentives. Private insurance companies may play a significant role here. In addition to judging risks according to the usual parameters damage potential and probability, other criteria such as ubiquity of hazard, persistence, and reversibility need to be considered (Renn and Sellke, 2001). Such a multicriteria-analysis can be modeled in principle, yet all insurance companies will have problems with risks where the uncertainty analysis does not provide reliable probability estimates.

\subsection{Type 4: Psychosomatic risks}

The nature of these types of risks is both ubiquitous and chronic. Psychosomatic risks occur at both personal and institutional levels. They can be identified in the form of some internal or mental health, often associated with depression (Kessler at al. 2003). Psychosomatic risk stems from the lack of orientation within a modernized society - one that struggles with proving convincing concepts for sense or meaning (Alexander, 2013). The issue here is how to find a way out of the current fashion of moral relativism and pluralism of values and worldviews. At an institutional level, psychosomatic risks are related to performance and lead to an inconsistency in both institutional values and behavior.

Table 1 provides a list of major risks that the Harvard School of Public Health has identified as main causes of death in the year 1990 and a prediction of these main causes of death or chronic diseases for the year 2020 (Klinke and Renn, 1999). One can clearly see that the authors believe that infectious diseases will be of minor importance in the year 2020 (which according to our analysis is rather doubtful) while lifestyle risks and accidents will occupy top positions in the list of the most likely causes of death or chronic diseases.

The 2020 Pandora box of risks contains familiar threats such as heart attacks and cancer but also less familiar risks such as depressions and brain disorders. The list demonstrates that the balance between mind and soul, a vital condition for individual well-being, is in jeopardy. One of the main challenges in this respect will be the reconciliation between the material opportunities and the psychological and spiritual needs of humans.

Table 1. Likely Developments of Risks.

\begin{tabular}{|ll|}
\hline Hazard Statistics: & \\
Causes of Death and & Chronic Diseases \\
$\mathbf{1 9 9 0}$ & $\mathbf{2 0 2 0}$ \\
\hline infections & heart attacks \\
diarrhea & depressions \\
death at birth & accidents \\
depressions & brain disorders \\
heart attack & chronic bronchitis \\
cancer & cancer \\
\hline
\end{tabular}

The risks associated with electromagnetic fields can also be placed in this context (Wiedemann and Schütz, 2005). It is not a question of physical malfunctions that underlie objective verifiable data, but it concerns subjective perceptions or subjective feelings impeding on efficiency, which can lead to psychosomatic malfunctions. The decisive aspect is the question on the subjective risk perception of the affected people. The risks associated with electromagnetic fields have become a p opular subject of the media coverage and move into the centre of public debate. Electromagnetic fields are perceived as risks due to the range of results from professional as well as from allegedly professional risk studies. The vast majority of serious scientific researches come to the conclusion that electromagnetic fields generate effects, which are usually not hazardous for the vast majority of human beings, i.e. neither epidemiological nor toxicological significant changes are noticeable (Kostoff and Lau, 2013).

The risk debate about electromagnetic fields also reflects a d iscussion among experts where trust and reliability are challenged (Renn, 2006). Recognized scientists often maintain antagonistic standpoints leading to a situation that scientific reliable knowledge is doubted by the public. Every expert's opinion provokes counter expertise. Especially, thresholds are 
subjects of public distrust. The degree of uncertainty among experts is interpreted as ignorance or as bribery (Schütz and Wiedemann, 2005).

Psychosomatic risks exhibit cultural variations, and the challenge is to find a set of universal values that overcome these differences. Where there are none, or alternately, a 1 ot of collective values that need to be bridged there is a need to invent these universal values. The constraints for achieving a s ocietal response to these psychosomatic risks are the diversity of humans across the globe, and the plurality of views they hold. The increasing divide between the rich and poor makes the search more difficult and reduces the credibility of this mission.

There will be a rise in the number of psychosomatic responses, and there is no clear countertrend or civil force that would drive towards this to this. This type of risk requires real action, as it decreases productivity and can also decrease trust in political institutions. In contrast to somatic illnesses that are of a t emporary nature, psychosomatic illnesses are chronic. Individuals who suffer from this trend tend to isolate themselves from society, and become more of a drain than an asset to society.

In terms of the IRGC risk strategies, the resilience and adaptation model may be the best to pursue for this category of emerging risks. One needs to strengthen the resilience of people to find their own identity in a world of plural identities and of an inexhaustible appetite of the intellectual elite to deconstruct existing worldviews ${ }^{17}$. At the same time, societal institutions can help individuals to develop better adaptive capacities to cope with orientation crisis and develop more resistance against self-doubts.

\subsection{Type 5: Social risks to society}

Social risks are understood in this context as consequences of social actions that impact human health and the environment or their perception (excluding genuine social risks such as lack of education or shelter). Most prominent risks here are violence, crime, terrorism and sabotage (Findlay, 2013; Zimmermann, 2011). These risks have become particularly prominent

17 "Modernity cannot survive in a purely objective and rational form. It needs romance, a connection to the inner life. Modernity must be connected to subjectivity if the modern self is to be repaired and thrive". From: Alexander (2013), p. 146, since the attack on the World Trade Center. Many analysts believe that, apart from infectious diseases, most lives are lost due to human induced violence (ca. 13 million fatalities annually due to infectious diseases; 79,000 fatalities annually due to natural hazards; ca. 8000 fatalities due to technological hazards; between 25 million each year thorough violence) ${ }^{18}$. Human violence may become even a more prominent risk in modern interconnected societies since the infrastructure offers more opportunities for inducing break-down damages with relatively little effort. Large water reservoirs for drinking water, high buildings, locally concentrated chemical facilities; mass-flow transport lines, large-scale technologies and many other new developments increase the overall vulnerability of societies. Such vulnerabilities invite potential terrorists to take advantage of this situation ${ }^{19}$. The probability of terrorist attacks is likely to increase due to (Moghaddam, 2010):

- the widening of the gap between the $10 \%$ richest and $10 \%$ poorest countries (same is true on the individual basis) ${ }^{20}$

- the political tensions due to hegemonic power struggles after the Cold War;

- $\quad$ increase of fundamentalist positions in the world;

- dissatisfaction of particular groups with globalization processes and

- lack of social integration for a growing amount of displaced intellectuals in many countries.

The attack on the World Trade Center has already been a major challenge to risk management institutions, in particular re-insurance companies (Hartwig, 2002). Most of the targets that are attractive to terrorists represent "accomplishments" of capitalist economies. In

18 Data on natural, technological and health hazards in OECD: (2003), p. 14-15; data on violence in: L. Richardson (1990): Statistics of Deadly Quarrels. Boxwood Press: Pittsburg; and P. Swabury and A. Codevilla (1989): War: Ends and Means. Basic Books: New York

19 OECD: (2003), p. 209.

20 The Institute for Policy Studies tracks the gap between CEO's and American workers. The average ratio between salaries for a ch ief executive and American worker ranges around 350 to one. The avaerage pay in the United States is about $\$ 20$ per hour. The CEO of Wal Mart earns \$30-million a year, which is $\$ 15,000$ per hour: about the wages of a year-round minimumwage worker. Taken from: http://chronicle.com/ blogs/brainstorm/economists-fail-to-justify-obscene-ceo -pay/25500, (access: July 15, 2014). 
most cases these targets are well-insured. The premiums, however, were calculated on the assumption of a low probability of terrorist attacks, if this had been included at all.

Other human-induced risks may get overlooked under the deep shock released by the recent terrorists attacks. Yet, civil war, crime, and anomy (absence of legal enforcement) cost many more lives than terrorism (Lozano, 2013). Most of these risks are not addressed by any risk governance regimes. Yet the impacts of violent behavior produce many indirect effects such as an increase in infectious diseases, famines, technological failures and many others.

There is a second class of social risks that are related to changes in values, perceptions and attitudes. These risks are related to social definitions of what is framed as damage, causing agent or blame. For example, the term "human health" has been gradually expanded to include aspects of well-being and self-reliance (Emson, 1987). Medical treatment is extended to those who are not ill but feel deprived in one way or the other. Lifestyle pharmaceuticals as well as wellness treatments are telling examples of such a new mental image of health. Obviously changes in what is included in health care have major ramification on risk management and its social cost.

Changes in values also have repercussions on issues such as burden of proof (in tort cases), imposition of strict liability or degree of evidence for making someone accountable for any damage. Even minor changes in the liability system can trigger large changes in damage claims. With respect to social value changes, it is difficult to predict the most likely developments of the future. But a few trends seems to prevail (Wilkinson, 2013):

Affluent societies become more preoccupied with the notion of health and well-being. This will be reinforced by the trend of aging. The share of the population aged above $60 \mathrm{is}$ expected to reach $33 \%$ in 2050 in developed countries, compared to $19 \%$ in $2000^{21}$. At the same time, new technologies and pharmaceutical developments will enable the medical staff to tailor the treatment to individual needs of patients (Hayes et al. 2014). The costs for such treatments will increase exponentially. It is still unclear how

21

OECD (2003), p. 18.

social security systems will be able to handle such cost increases.

- Modern science provides improved and more detailed models of complex cause-effect relationships. These new insights will help to identify causes for diseases or other type of damages that are presently associated with random events or background noise. This may lead to the emergence of surprises and new insights that may force risk managers to change their activities. Moreover such surprises trigger losses of public trust and confidence in risk management institutions.

- Legal reform in developed countries tends to emphasize the protection of the weaker part in a lawsuit. In particular legal systems with a strong jury influence make often economically powerful actors more accountable for their actions even if the evidence is less compelling. Compensation is also likely to be awarded if the "victim" appears to be less informed than necessary in order to make prudent decisions on consumption. Risk producers will be obliged to assure informed consent by those who use their products or are exposed to risks. In contrast to earlier times, it will make hardly any difference whether consumption or exposure have been voluntary or not. The main issue will be access to full information and an active effort by the risk producer for making all potential hazards known to the potential victims (Odugbemi, 2008).

Taking all three trends together risk management institutions (public and private) may face an accelerated challenge. The social definition of what is regarded as harm includes more and more factors that were formerly interpreted as misgivings. In addition, science provides better models for new causal relationships and the legal system relaxes its provisions for what is called "hard evidence". All three trends reinforce each other and will most likely lead to more developments framed as risks that, in turn, will demand collective risk reduction efforts. This trend may be counteracted, however, if a serious political movement towards more personal accountability of the consumer (individual and social) were to be launched.

What can be done to develop a suitable strategy for dealing with social risks? May be a v ersion of the strategy "Modifying the risk appetite in line with a new 
risk" is appropriate. This strategy would, suggest that society places more responsibility on the individual and his or her own network to deal with social risks and to find an appropriate balance between opportunities given by plurality, increased options and individuality and the risks that go along with the loss of unambiguous values and group identity. A necessary condition for this is equal access to these opportunities, i.e. a co llective action to overcome the growing gap in the distribution of career, education and living opportunities (Beck, 2013).

\subsection{Type 6: Knowledge management risks (promoter)}

Knowledge management risks refer to the quality and availability of information necessary to manage or reduce a $g$ iven risk. Although it may pose a risk in itself, it serves in most cases as a promoter or modifier of other risk types. If a high quality knowledge management system is in place, the likelihood that any of the other risks become much more serious than anticipated, decreases considerably. It is closely related to system breakdown and amplifier risks.

Knowledge management describes the process of sorting through the high amount of information available and finding the right knowledge for the right purpose. This has always posed problems for society, but it now presents substantial risks to society, due to the high volumes of stored, possessed and generalized knowledge available (Hayward and Personick, 19981999).

Knowledge management risks could be a cau sal factor in the collapse of a particular system, or a mitigating factor in disaster management. One aspect of this risk is the challenge of dealing with uncertainty, and the need to select the right knowledge. A critical issue is acknowledgement of the boundaries of knowledge or ignorance, and the issues of framing, but achieving this is complicated by the abundance of information about certain aspects of knowledge, which can make these boundaries more difficult to distinguish (Siegrist and Cvetkovich, 2000). Knowledge can be of a national, supranational or localized in character, and knowledge management needs to incorporate all these levels. For example, many of the Agenda $21 \mathrm{pr}$ ocesses on community collapsed because no universal criteria could be found to measure the sustainability of a particular community (Bebbington and Gray, 2001).
Societal management of knowledge management risks would have to include a shift in emphasis by research councils and sponsors to the identification and classification of information that is at present unavailable, and an expansion of knowledge outside the realm of the classic science fields. For example, decision-makers should be aware of the degree of uncertainty with regard to the consequences of nanoparticles in food and cosmetics. There is also a need for a better information brokering system, which cannot be fulfilled by the traditional universities. The development towards open access to all kind of knowledge pools leads to the need of having global knowledge brokers (not only providers) that help people as well as institutions to navigate through the jungle of knowledge claims.

The constraints on the management of these risks are the difficulties in establishing the criteria for quality control of knowledge, and the degrees of freedom required for enlarging the knowledge base. There are many discussions on the virtual information transfer systems, but it is difficult to decide on the parameters needed to meet this function. One of the major factors in remaining competitive in a global market is the ability of global players to have fast and reliable information retrieval systems at hand. This is particularly true for risk management institutions.

Knowledge management risks serve more as promoters or attenuators of risks that constitute risks themselves. The IRGC protocol has been designed to provide a orientation for selecting and processing knowledge. $\mathrm{S}$ uch orientations for knowledge management are needed for all the risk types that were discussed above. The better and the more accurate the knowledge basis the better the conditions for choosing the most appropriate risk management strategy.

\section{Conclusions}

To establish a framework for good governance on emerging risks, a stringent, logically well-structured and promising decision-making process is required. Risk managers need substantive but flexible guidelines that are globally applicable to manage emerging risks. Good governance seems to rest on the three components: knowledge, legally prescribed procedures and social values. It has to reflect specific functions, from early warning (radar function), over new assessment and management tools leading to improved methods of 
effective risk communication and participation. Criteria of good governance have been discussed in many contexts (Hubbard, 1999; OECD, 1995). They need to be transferred to risk-related issues and operationalized so that best practices can be identified and recommended. Central items to be addressed are sound scientific expertise, burden of proof, consistency and coherence, non-discrimination, proportionality and costbenefit examination. In addition, governance structures should reflect criteria such as transparency, openness, accountability, effectiveness, and mediation of different/conflicting interests.

The IRGC emerging risk protocol is a first attempt to provide such an orientation for dealing with emerging threats. It has not been finalized and is under review by scholars and practioners from many countries and risk domains. Yet a first application of the protocol in this article shows that it has the potential to identify emerging risk areas and suggest strategies to deal with many of the complex and ambiguous challenges posed by emerging risks worldwide.

The promises of new developments and technological breakthroughs need to be balanced against the potential evils that the opening of Pandora's box may entail. This balance is not easy to find as opportunities and risks are emerged in a cloud of uncertainty and ambiguity. The dual nature of risk as a potential for technological progress and as a s ocial threat demands a dual strategy for risk management. It will be one of the most challenging tasks of the world risk management institutions to investigate and propose more effective, efficient and reliable methods of emerging risk assessment and risk management while, at the same time, ensure the path towards new innovations and technical breakthroughs. The late Aaron Wildavsky (1979) paraphrased this problem by giving one of his seminal articles the provocative title: "No risk is the highest risk of all". Poor and inadequate risk management, however, appears to be the second highest risk and a suitable candidate for disaster. The IRGC remerging risk protocol might help risk managers to acquire necessary knowledge, articulate the insightful scenarios and develop the most appropriate risk management strategies for finding the right balance between opportunities and risks.

\section{References}

J. C. Alexander, The Dark Side of Modernity (Polity, Cambridge, 2013), p.144.
T. Aven and O. Renn, The role of quantitative risk assessments for characterizing risk and uncertainty and delineating appropriate risk management options, with special emphasis on terrorism risk, Risk Analysis 29 (4) (2009), 587-600

R. Barfield, Risk Appetite-How Hungry are You? PriceWaterhouse-Coopers Journal, Special Risk Management Edition, (PWC, London, 2007), http://docsfiles.com/pdf appetite.html (access: August 2, 2014).

A. M. Barrett, Analyzing current and future catastrophic risks from emerging-threat technologies, Current Research Project Narratives, Online Publication, 63 (2014), http://research.create.usc.edu/current_synopses/63 (access August 5, 2014).

J. Bebbington and R. Gray, An account of sustainability: failure, success and a $\mathrm{r}$ econceptualization, Critical Perspectives on Accounting 12 (5) (2001) 557-588.

U. Beck. Risk Society: Towards a New Modernity. (Sage, London, 1992).

U. Beck, Risk society revisited: theory, politics and research programmes, in: The Risk Society and Beyond. Critical Issues for Social Theory, eds. B. Adam, U. Beck and J. van Loon (Sage, Thousand Oaks, USA, 2000), pp. 211229

U. Beck, Why "class" is too soft a category to capture the explosiveness of social inequality at the beginning of the twenty-first century, Britisch Journal of Sociology 64 (1) (2013) 63-73.

P.G. Bennet, Applying the precautionary principle: a conceptual framework, in: Foresight and Precaution, Volume 1, eds. M.P. Cottam, D.W. Harvey; R. P. Paper and J. Tait (A.A. Balkema, Rotterdam and Brookfield, 2000), pp. 223-227.

R. Black, N. W. Arnell, W. N. Adger, D. Thomas and A. Geddes, Migration, immobility and displacement outcomes following extreme events, Environmental Science \& Policy 27 (2013) 32-43.

BSE Inquiry, Executive summary of the report of the inquiry, (2001), Available online at http://www.bseinquiry.gov.uk/ report/volume1/toc.htm (Access: July 25, 2014).

Center for Disease Control and Prevention (CDC): Pandemic Influenza: A Planning Guide for State and Local Officials, Document 2.1. CDC: Atlanta, 2000.

G. Charnley and E.D. Elliott, Risk versus precaution: a false dichotomy, in: Foresight and Precaution, Volume 1, eds. M.P. Cottam, D.W. Harvey; R. P. Paper and J. Tait (A.A. Balkema, Rotterdam and Brookfield, 2000), pp. 209-212.

T. Dietz, E. Ostrom and P. Stern, The struggle to govern the common, Science 302 (2003) 1907-1912.

K. Dressel, The cultural politics of science and decisionmaking, an anglo-german comparison of risk political cultures: the BSE case, (2000), Available online at http://bse.airtime.co.uk/dressel.htm (Access: July 30, 2014).

H. E. Emson, Health, disease and illness: matters for definition, CMAJ 136 (1987) 811-813. 
A. Falk, E. Fehr and U. Fischbacher, Appropriating the commons: a theoretical explanation, in: The Drama of the Commons, eds. T. Dietz, N. Dolšak, E. Ostrom, P. Stern, S. Stonich and E. Weber (National Academy Press, Washington, DC, 2002), pp. 157-191.

M. J. Findlay, Governing Through Globalised Crime (Willan, Cullumpton, UK, 2013).

M. Fischer-Kowalski and C. Amann, Beyond IPAT and Kuznets curves: globalization as a vital factor in analysing the environmental impact of socio-economic metabolism, Population and Environment, 23 (1) (2001), 7-47.

G. C. Gallopin, Linkages between vulnerability, resilience, and adaptive capacity, Global Environmental Change 16 (2006) 293-303.

L. Garrett, The Coming Plague: Newly Emerging Diseases in a World Out of Balance (Penguin Books, San Francisco, 1995)

W. H. Gaze, S. M. Krone, D. G. Larsson, X .Z. Li, J. A. Robinson, P. Simonet and Y. G. Zhu, Influence of humans on evolution and mobilization of environmental antibiotic resistome. Emerging Infectious Diseases, 19 (7) (2013), doi: 10.3201/eid1907.120871.

A. V. Gheorghe and D. V. Vamanu, Complexity induced vulnerability, International Journal of Critical Infrastructures 1(1) (2004) 76-84.

A. Grobe, O. Renn and A. Jaeger, Risk Governance of Nanotechnology Applications in Food and Cosmetics, IRGC, Geneva, 2008.

S. E. Håberg, L. Trogstad, N. Gunnes, A. J. Wilcox, H. K. Gjessing, S. O. Samuelsen and C. Stoltenberg, Risk of fetal death after pandemic influenza virus infection or vaccination, New England Journal of Medicine 368 (4) (2013) 333-340.

R. Hartwig, One Hundred Minutes of Terror That Changed the Global Insurance Industry Forever. Public Policy Paper. Insurance Information Institute: New York. (2002).

D. F. Hayes, H. S. Markus, R. D. Leslie and E. J.Topol, Personalized medicine: risk prediction, targeted therapies and mobile health technology, BMC Medicine 12 (1) (2014) 37-46.

G. A. Hayward and S.D. Personick, Protecting the infrastructures of the information age, Telecordia Exchange Magazine 23 (1998-1999) 23-42.

M. P. Healey and G. P. Hodgkinson, Troubling futures: scenarios and scenario planning for organizational decision making, in: The Oxford Handbook of Organizational Decision, eds. D. G. P. Hodgkinson and W. H. Strabuck (Oxford University Press, Oxford, 2012), pp. 565-587.

J. Helgeson, S. van Der Linden and I. Chabay, The role of knowledge, learning and mental models in public perceptions of climate change related risks, in: Learning for Sustainability in Times of Accelerating Change, eds. D. A. Wals and P. B. Corcoran (Academic Publishers, Wageningen, 2013), pp. 329-346.
M. Helmer and D. Hillhorst, Natural disaster and climate change, Disaster (Special Issue on Climate Change and Disasters), 30 (1) (2006) 1-4.

Y. Hémond, and B. Robert, Evaluation of state of resilience for a cr itical infrastructure in a co ntext of interdependencies, International Journal of Critical Infrastructures 8 (2/3) (2012), 1-18.

R. Hubbard, Criteria of Good Governance, Optimum, the Journal of Public Sector Management 30(2) (1999) 37-50.

P. Iadociola and A. Shupe, Violence, Inequality and Human Freedom, Third Edition (Rowman \& Littlefield, Lanham, USA, 2013), pp. $451 \mathrm{ff}$.

IRGC, Emerging Risks. Sources, Drivers and Governance Issues. IRGC: Geneva, 2009.

B. G. Jones and W.A. Kandel, Population growth, urbanization, disaster risk and vulnerability in metropolitan areas: a co nceptual framework, in: Environmental Management and Urban Vulnerability, Discussion Paper No. 168, A. Kreimer and M. Munasinghe (The World Bank, Washington D.C. ,1992).

B. Joy, Why the Future Doesn't Need Us, Wired (April 8, 2000), 2.

R. E. Kasperson, O. Renn, P. Slovic, H. S Brown, J. Emel, R. Goble, J. X. Kasperson and S. Ratick, The social amplification of risk. a conceptual framework, in: The Earthscan Reader in Risk \& Modern Society, eds. R. Löfstedt and L. Frewer (Earthscan, London, 1998), pp. 149-162.

R. C. Kessler, P. Berglund, O. Demler, R. Jin, D. Koretz, K. R. Merikangas and et al, The epidemiology of major depressive disorder: results from the national morbidity survey replication (NCS-R). Journal of the American Medical Association 289 (2003) 3095-3105.

A. Klinke and O. Renn, Prometheus Unbound. Challenges of Risk Evaluation, Risk Classification, and Risk Management, Working Report No-.153, Center of Technology Assessment in Baden-Württemberg, Stuttgart, (1999), p. 8.

A. Klinke and O. Renn, Precautionary principle and discursive strategies: classifying and managing risks, Journal of Risk Research 4(2) (2001) 159-174.

A. Kocharov, EFSA's identification of emerging risks, European Food and Feed Law Review, 3 (2010) 144-155.

J. Koricheva and J. Gurevitch, Place of meta-analysis among other methods of research synthesis, in: Handbook of Meta-analysis in Ecology and Évolution, eds. J. Koricheva, J. Gurevitch and K. Mengersen (Princeton University Press, Princeton, 2013), pp. 3-13.

R. N. Kostoff and C. G. Lau, Combined biological and health effects of electromagnetic fields and other agents in the published literature, Technological Forecasting and Social Change 80 (7) (2013) 1331-1349.

W. Kröger, Critical infrastructures at risk: a need for a new conceptual approach and extended analytical tools, Reliability Engineering and System Safety 93 (2008) 17811787 
E. K. Lipp, A. Huq and R. Colwell, Effects of global climate on infectious disease: the cholera model, Clinical Microbiology Review 15(4) (2002) 757-770.

T. Llanso, G. Tally, M. Silberglitt and T. Anderson, MissionBased Analysis for Assessing Cyber Risk in Critical Infrastructure Systems, in: Critical Infrastructure Protection VII, Volume 417, eds. J. Butts and S. Shenoi (Springer, Berlin and Heidelberg, 2013), pp 201-214.

R. Lozano, M. Naghavi, K. Foreman, S. Lim, K. Shibuya, V. Aboyans and M.Cross, Global and regional mortality from 235 causes of death for 20 age groups in 1990 and 2010: a systematic analysis for the global burden of disease study 2010. The Lancet 380 (9859) (2013) 2095-2128.

O. Mahul and A. Gohin, Irreversible decision making in contagious animal disease control under uncertainty: an illustration using FMD in Brittany, European Review of Agricultural Economics 26 (1999) 39-58.

G. R. Marshall, Transaction costs, collective action and adaptation in managing complex social-ecological systems, Ecological Economics 88 (2013) 185-194.

C. Mazri and M.-V. Florin, Emerging Risk Governance Protocol, Summary Report, IRGC: Lausanne, 2014.

F. M. Moghaddam, The New Global Insecurity: How Terrorism, Environmental Collapse, Economic Inequalities, and Resource Shortages are Changing Our World (Praeger, Santa Barbara, 2010).

National Research Council, Advancing the Science of Climate Change (National Academies Press, Washington, D. C. 2010), pp. 102-105.

H.-P. Neitzke, M. Calmbach, D. Behrendt, Kleinhückelkotten, E. Wegner, and C. Wippermann, Risks of ubiquitous information and communication technologies, GAIAEcological Perspectives for Science and Society 17 (4) (2008), 362-369.

H. Odugbemi, Public opinion, the public sphere, and quality of governance: an exploration, in: Governance Reform under Real-World Condition Citizens, Stakeholders, and Voic, eds. H. Odugbemi and T. Jacobson (The World Bank, Washington, D. C., 2008), pp. 15-38.

OECD, Participatory Development and Good Governance, OECD: Paris, 1995.

OECD, Emerging Risks in the 21st Century: An Agenda for Action. OECD: Paris, 2003.

C. Perrow, Normal Accidents (Basic Books, New York, 1984).

J. B. Randall, D. L. Turcotte and W. Klein, Reduction and Predictability of Natural Disasters. Vol. XXV. Santa-FeeInstitute Studies in the Sciences of Complexity. AddisonWesley: New York. (1996)

O. Renn, Risk communication insights and experiences in the EMF Debate, in: Mobile EMF and CommunicationInternational Perspectives, ed. M. Nishizawa (National Institute for Earth Science and Disaster, Tokyo and Tsukuba, 2006), pp. 87-101.

O. Renn, Risk Governance. How to Cope with Uncertainty in a Complex World (Earthscan, London, 2008)
O.Renn, Das Risikoparadox. Warum wir uns vor dem Falschen fürchten (Fischer, Frankfurt am Main, Germany, 2014)

O. Renn and A. Klinke, Complexity, uncertainty and ambiguity in inclusive risk governance, in: Risk and Social Theory in Environmental Management, eds. T.G. Measham and S. Lockie (CSIRO Publishing, Melbourne, Australia, 2012), pp. 59-76.

O. Renn, A. Klinke and M. van Asselt, Coping with complexity, uncertainty and ambiguity in risk governance: a synthesis, AMBIO, 40 (2) (2011) 231-246.

O. Renn and P. Sellke, Risk, society and policy making: risk governance in a complex world, International Journal of Performability Engineering, 7 (4) (2001) 349-366.

E. A. Rosa and T. Dietz, Global transformations: PaSSAGE to a new ecological era, in: Human Footprints on the Global Environment, eds. E.A. Rosa, A. Diekmann, T. Dietz and C.C. Jaeger (MIT Press, Cambridge, USA, 2010), pp. 145.

E. A. Rosa, R. York and T. Dietz, Tracking the anthropogenic drivers of ecological impacts. AMBIO: A Journal of the Human Environment, 33(8) (2004) 509-512.

H. Schütz and P. M. Wiedemann, How to deal with dissent among experts. Risk evaluation of EMF in a scientific dialogue, Journal of Risk Research 8 (6) (2005) 531 - 545.

J. A. Shatkin, Defining risk assessment and how it is used for environmental protection, and its potential risk for managing nanotechnology risk, in: Nantechnology. Health and Environmental Risk, ed. J. A. Shatkin (CRC Press, Boca Raton, USA, 2013), pp. 54.

M. Siegrist and G. Cvetkovich, Perception of hazards: the role of social trust and knowledge, Risk Analysis 20 (2000) 713-719.

P. C. Stern, Design principles for governing risks from emerging technologies, in: Structural Human Ecology. New Essays in Risk, Energy and Sustainability, eds. T. Dietz and A. Jorgenson (WSU Press, Pullman, Washington, 2013), pp. 91-120.

R. E. Ulanowicz, Circumscribed Complexity in Ecological Networks, in: Advances in Network Complexity, eds. M. Dehner, A, Mowshowitz and F. Emmert-Streib (Wiley Onlie Library, DOI: 10.1002/9783527670468.ch11, 2013), pp. 249-258.

P. M. Wiedemann and H. Schütz, The precautionary principle and risk perception: experimental studies in the EMF Area, Environmental Health Perspectives 113 (4) (2005) 402 405.

A. Wildavsky, Views: No Risk Is the Highest Risk of All: A leading political scientist postulates that an overcautious attitude toward new technological developments may paralyze scientific endeavor and end up leaving us less safe than we were before, American Scientist 3 (1979) 3237.

A. Wilkinson, Elahi and E. Eidinow, Riskworld Scenario, Risk Research, 6 (1-4) (2013) 297-334.

Wissenschaftlicher Beirat der Bundesregierung Globale Umweltveränderungen (WBGU), World in Transition: 
Water Resource Management, Annual Report of 1998 (Springer, Heidelberg, 1999).

E. Zimmermann, Globalisierung und $\mathrm{T}$ errorismus, in: Globalisierung im Fokus von Politik, Wirtschaft, Gesellschaft, eds. T. Mayer, R. Meyer, L. Miliopoulos, H. P. Ohl and E. Weede (VS Verlag für Sozialwissenschaften, Wiesbaden, Germany, 2011), pp. 183-198. 